\title{
Neutrophil extracellular traps induce aggregation of washed human platelets independently of extracellular DNA and histones
}

Omar Elaskalani, Norbaini Binti Abdol Razak and Pat Metharom *i]

\begin{abstract}
Background: The release of neutrophil extracellular traps (NETs), a mesh of DNA, histones and neutrophil proteases from neutrophils, was first demonstrated as a host defence against pathogens. Recently it became clear that NETs are also released in pathological conditions. NETs released in the blood can activate thrombosis and initiate a cascade of platelet responses. However, it is not well understood if these responses are mediated through direct or indirect interactions. We investigated whether cell-free NETs can induce aggregation of washed human platelets in vitro and the contribution of NET-derived extracellular DNA and histones to platelet activation response.

Methods: Isolated human neutrophils were stimulated with PMA to produce robust and consistent NETs. Cell-free NETs were isolated and characterised by examining DNA-histone complexes and quantification of neutrophil elastase with ELISA. NETs were incubated with washed human platelets to assess several platelet activation responses. Using pharmacological inhibitors, we explored the role of different NET components, as well as main platelet receptors, and downstream signalling pathways involved in NET-induced platelet aggregation.

Results: Cell-free NETs directly induced dose-dependent platelet aggregation, dense granule secretion and procoagulant phosphatidyl serine exposure on platelets. Surprisingly, we found that inhibition of NET-derived DNA and histones did not affect NET-induced platelet aggregation or activation. We further identified the molecular pathways involved in NET-activated platelets. The most potent single modulator of NET-induced platelet responses included NET-bound cathepsin G, platelet Syk kinase, and P2Y 12 and allbB3 receptors.

Conclusions: In vitro-generated NETs can directly induce marked aggregation of washed human platelets. Pre-treatment of NETs with DNase or heparin did not reduce NET-induced activation or aggregation of human washed platelets. We further identified the molecular pathways activated in platelets in response to NETs. Taken together, we conclude that targeting certain platelet activation pathways, rather than the NET scaffold, has a more profound reduction on NET-induced platelet aggregation.
\end{abstract}

Keywords: Neutrophil, Neutrophil extracellular traps, Platelet, Aggregation, DNA, Histones, Cathepsin G

\footnotetext{
* Correspondence: pat.metharom@curtin.edu.au

Platelet Research Laboratory, School of Pharmacy and Biomedical Sciences, Curtin Health and Innovation Research Institute, Faculty of Health Sciences, Curtin University, Bentley Campus, Office 160, Building 305, Kent Street, Bentley, Perth, WA 6102, Australia
}

(c) The Author(s). 2018 Open Access This article is distributed under the terms of the Creative Commons Attribution 4.0 International License (http://creativecommons.org/licenses/by/4.0/), which permits unrestricted use, distribution, and reproduction in any medium, provided you give appropriate credit to the original author(s) and the source, provide a link to the Creative Commons license, and indicate if changes were made. The Creative Commons Public Domain Dedication waiver (http://creativecommons.org/publicdomain/zero/1.0/) applies to the data made available in this article, unless otherwise stated. 


\section{Background}

Neutrophils are well known for their crucial role in innate immunity, providing the first line of defence against pathogens through multiple mechanisms [1]. The discovery of a relatively new antimicrobial mechanism, whereby activated neutrophils expel their DNA and proteins forming an extracellular matrix, termed neutrophil extracellular traps (NETs) [2], has gained much interest recently. NETs possess antimicrobial function either by entrapping and immobilising pathogens or presentation of NET-bound antimicrobial proteins [2, 3]. However, NETs can serve as more than just a host defence mechanism, as studies have implicated the role of NETs in inflammatory and autoimmune diseases and pathological conditions including thrombosis [4]. Notably, as the role of NETs in thrombosis is being investigated extensively in recent times, there is potential for NETs to not only serve as therapeutical target for thrombotic diseases but several other clinical conditions such as diabetes, systemic lupus erythematosus, pre-eclampsia and certain types of cancers, all which are known to be associated with increased risk of thrombosis [5-8].

Increasing number of studies are recognising NETs as a procoagulant surface, which is capable of promoting thrombosis both in vitro and in animal models of deep vein thrombosis and arterial thrombosis [9-13]. The NET structure can serve as a scaffold for platelet adhesion and aggregation [9, 14] thus providing a platform for the subsequent formation of thrombi. Furthermore, NETs have been shown to directly promote the activation of intrinsic coagulation pathway leading to thrombin generation [15]. Besides intact NETs being capable of activating coagulation, several components within the NET structure have been reported to activate platelets and initiate or promote coagulation. Cell-free DNA, which makes up the major backbone of NETs, has previously been shown to activate thrombin generation via the intrinsic pathway of coagulation [16]. The second most abundant constituent and protein found on NETs, extracellular histones, have been studied extensively and known to activate platelets and promote coagulation through multiple mechanisms [9, 17-19]. For example, histones are capable of generating thrombin in the presence of plasma and activating platelet aggregation which has been suggested to be mediated through toll-like receptor (TLR) 2 and TLR 4 [18]. However, the involvement of TLRs in platelet aggregation is not clear as Clark et al. have shown that LPS induced platelet activation but not aggregation [20] Furthermore, neutrophil granular enzymes that are bound to NETs such as neutrophil elastase (NE) and cathepsin G (Cat G), can separately promote coagulation and thrombus growth by facilitating intravascular fibrin formation and degrading tissue factor pathway inhibitor [21], while myeloperoxidase (MPO) can prime platelets [22].

Collectively, NETs are a potentially potent agonist of platelet activation and promoter of coagulation, thereby amplifying and supporting thrombus formation. However, despite many studies reporting NETs as promoters of thrombosis, these studies were conducted in whole blood assays or in the presence of plasma, implicating a role of plasma coagulation factors. Thus the capacity of intact cell-free NETs to directly activate washed platelets is not clearly understood. In this study, we investigated the effect of NETs on platelet function including aggregation, secretion, and surface expression of receptors. We also begin to determine molecular mediators and signalling pathways by examining the effect of antagonists of specific NET components and antiplatelet drugs, on the impact of NETs on platelet activation.

\section{Methods \\ Materials}

Purified anti-human TLR2, TLR4 blocking antibodies and their matching isotype controls were obtained from BioLegend, Inc., USA. Bay 61-3606 and Phorbol 12-myristate 13-acetate (PMA), ticagrelor and Cell Detection ELISA PLUS kit were from Sigma-Aldrich, Australia. ML-171, aspirin, RGDS, cathepsin G inhibitor I, neutrophil elastase inhibitor (1-(3-methylbenzoyl)-1$\mathrm{H}$-indazole-3-carbonitrile), myeloperoxidase inhibitor 1 (4-Aminobenzoic acid hydrazide), losartan were obtained from Cayman Chemical, USA. Abciximab (ReoPro) and low molecular weight heparin (Clexane enoxaparin sodium) were from Eli Lilly and Sanofi Aventis Australia Pty Ltd., respectively. DNAse I solution was purchased from STEMCELL Technologies Australia Pty Ltd. Collagen and thrombin were from Chrono-log Corporation, USA. Human PMN Elastase ELISA kit was obtained from Abcam Biotechnology, Cambridge, UK.

\section{Preparation of washed human platelets}

Blood was drawn from healthy volunteers into a syringe containing acid-citrate-dextrose (ACD; 1:7 ( $\mathrm{v} / \mathrm{v})$ with informed consent in concordance with the Curtin University Human Research Ethics Committee (approval number HR54/2014). Blood donors were medication-free 2 weeks prior to the day of donation. Washed platelets were prepared, with some modifications, as previously described [23, 24]. Briefly, blood was centrifuged at $150 \times \mathrm{g}$ for $20 \mathrm{~min}$. Platelet-rich plasma (PRP) was collected and centrifuged at $800 \mathrm{x} g$ for $10 \mathrm{~min}$ in the presence of $1 \mu \mathrm{M}$ prostaglandin E1 (PGE1; Cayman Chemical). Platelets were then washed three times in CGS buffer (14.7 $\mathrm{mM}$ trisodium citrate, $33.33 \mathrm{mM}$ glucose and $123.2 \mathrm{mM} \mathrm{NaCl}, \mathrm{pH} 7$ ), in the 
presence of PGE1 $(1 \mu \mathrm{M})$. Platelets were adjusted to $1 \times$ $10^{9} / \mathrm{mL}$ with calcium-free Tyrode-Hepes buffer $(5 \mathrm{mM}$ HEPES, $5.5 \mathrm{mM}$ glucose, $138 \mathrm{mM} \mathrm{NaCl}, 12 \mathrm{mM}$ $\mathrm{NaHCO}_{3}, 0.49 \mathrm{mM} \mathrm{MgCl} 2,2.6 \mathrm{mM} \mathrm{KCl}, 0.36 \mathrm{mM}$ $\mathrm{NaH}_{2} \mathrm{PO}_{4}, \mathrm{pH}$ 7.4). Platelets were supplemented with $1.8 \mathrm{mM} \mathrm{CaCl}_{2}$ (final concentration) prior to experimentation.

\section{Preparation of neutrophils and cell-free neutrophil extracellular traps (NETs)}

Neutrophils were isolated from human blood using PolymorphPrep (Axis-Shield, Norway), with minor changes to the manufacturer's protocol. Briefly, blood anticoagulated with EDTA (2 mM) was layered over PolymorphPrep and centrifuged at $500 \times g$ for $40 \mathrm{~min}$. The neutrophil fraction was collected and washed twice at $4{ }^{\circ} \mathrm{C}$ in Hank's buffered saline solution (without calcium or magnesium) and resuspended in X-VIVO 15 media (Lonza, Switzerland). Neutrophil purity was $>95 \%$ as determined with a haematology analyser (Mindray, BC-VET2800). Cell-free NETs were isolated as previously described [25] with minor changes to the protocol. This method of NET isolation does not involve using DNase or EDTA [26], which may confound platelet response to NETs. Briefly, neutrophils $\left(2.5 \times 10^{6} / \mathrm{mL}\right)$ were stimulated with $500 \mathrm{nM}$ PMA for $3 \mathrm{~h}$ at $37{ }^{\circ} \mathrm{C}$ and $5 \%$ $\mathrm{CO}_{2}$. The supernatant, containing PMA, was discarded and the NET monolayer was detached with phosphate-buffered saline (PBS). The cell debris was pelleted by centrifugation at $480 \mathrm{x} g$ for $10 \mathrm{~min}$ at $4{ }^{\circ} \mathrm{C}$. The supernatant was further centrifuged at $15,000 \times \mathrm{x}$ for $20 \mathrm{~min}$ at $4{ }^{\circ} \mathrm{C}$ to pellet DNA then resuspended in PBS at $100 \mu \mathrm{l}$ per $1 \times 10^{7}$ of stimulated neutrophils to obtain cell-free NETs. Cell-free NETs were characterised by detecting DNA-histone complex and neutrophil elastase using Cell Detection ELISA PLUS kit (Sigma Aldrich) and Human PMN Elastase ELISA kit (Abcam), respectively. Cell-free NETs were incubated with platelets at $10 \%$ of final reaction volume (i.e. 1-volume NET solution to 9-volume platelets).

\section{Platelet aggregation assay}

Washed platelets $\left(3 \times 10^{8} / \mathrm{mL}\right)$ in Tyrode-HEPES buffer supplemented with $1.8 \mathrm{mM}$ calcium chloride were incubated in the presence of cell-free NETs $(10 \%$ of final reaction volume) and platelet aggregation was monitored at $37^{\circ} \mathrm{C}$ with continuous stirring at $1200 \mathrm{rpm}$ in a light transmission aggregometer (Model 700 Aggregometer, Chrono-log Corporation, USA) for at least $20 \mathrm{~min}$. Tyrode-HEPES buffer was used as a blank. Where inhibitors were used, platelets were pre-incubated for $15 \mathrm{~min}$ at $37{ }^{\circ} \mathrm{C}$ prior to incubation with NETs. Control samples were incubated with the corresponding volume of buffer.

\section{Platelet-dense granule secretion assay}

Platelet secretion was determined by measuring ATP release using luciferin/luciferase reagent (Chrono-Lume, Chrono-log Corporation, USA). Briefly, $90 \mu \mathrm{l}$ of platelets $\left(1 \times 10^{8} / \mathrm{mL}\right)$ in Tyrodes-HEPES buffer (with calcium) were incubated with $10 \mu \mathrm{l}$ of NETs with gentle shake at $37{ }^{\circ} \mathrm{C}$ for 1 and $10 \mathrm{~min}$ before adding $5 \mu \mathrm{l}$ of Chrono-Lume reagent. The luminescence was measured using Enspire Multimode Plate Reader (PerkinElmer, USA). Where anti-platelet drugs were used, platelets were pre-incubated with the drugs for $15 \mathrm{~min}$ at $37{ }^{\circ} \mathrm{C}$ before incubating with NETs.

\section{P-selectin exposure and allb $\beta 3$ activation}

Platelet activation was measured by detecting P-selectin and active-form $\alpha \operatorname{IIb} \beta 3$ on the platelet surface using flow cytometry. Where inhibitors were used, platelets were pre-incubated for $15 \mathrm{~min}$ at $37^{\circ} \mathrm{C}$ before adding NETs. Whenever inhibitors of components of NETs (i.e. DNAse I, cathepsin G, myeloperoxidase, and elastase inhibitors) were used, NETs were pre-incubated for $30 \mathrm{~min}$ at $37{ }^{\circ} \mathrm{C}$. The specificity of inhibitors used was also examined for their effect on thrombin $(0.1 \mathrm{U} / \mathrm{mL})$ and collagen $(5 \mu \mathrm{g} / \mathrm{mL})$-induced platelet activation. Inhibitor-, or vehicle-, treated washed human platelets $\left(1 \times 10^{8} / \mathrm{mL}\right)$ were treated with NETs $(10 \%$ of final volume) and stained with phycoerythrin-conjugated mouse anti-human CD62P (P-selectin) and fluorescein isothiocyanate-conjugated mouse anti-human PAC1 (active-form $\alpha \operatorname{IIb} \beta 3$ ), or suitable isotype control antibodies for $15 \mathrm{~min}$ in the dark. All antibodies were from BD Biosciences. Samples were analysed by flow cytometry (BD LSRFortessa ${ }^{\mathrm{Tw}}$ cell analyzer).

\section{Phosphatidylserine (PS) exposure}

Platelets $\left(3 \times 10^{8} / \mathrm{mL}\right)$ were incubated with NETs for $30 \mathrm{~min}$ at $37{ }^{\circ} \mathrm{C}$ with continuous stirring at $1200 \mathrm{rpm}$. Whenever inhibitors were used, NETs were pre-incubated for $30 \mathrm{~min}$ at $37{ }^{\circ} \mathrm{C}$. Thrombin $(0.1 \mathrm{U} /$ $\mathrm{mL}$ ) was used as positive control. Platelets were then stained with Annexin V-FITC (BioLegend, USA) in binding buffer according to manufacturer's instructions for $15 \mathrm{~min}$ in the dark. Samples were then washed in binding buffer and analysed by flow cytometry (BD LSRFortessa $^{\text {max }}$ cell analyzer).

\section{Antibodies and western blot}

Rabbit antibodies specific for p-Akt (Ser473), p-Erk1/2 (Thr202/Tyr204), p-Syk (Tyr352), p-Tyr1000 and $\alpha$-actinin were obtained from Cell Signalling Technology (USA). Platelets $\left(3 \times 10^{8} / \mathrm{mL}\right)$ were incubated with NETs (10\% of final reaction volume) at $37^{\circ} \mathrm{C}$ for 3 min with continuous stirring at $1200 \mathrm{rpm}$. Platelets were then lysed in Laemmli sample buffer supplemented with 
Protease/Phosphatase Inhibitor Cocktail (Cell Signalling Technology) and $\beta$-mercaptoethanol. Forty-five $\mu \mathrm{l}$ of protein sample was loaded per lane and separated by sodium dodecyl sulphate-polyacrylamide gel electrophoresis then transferred to a polyvinylidene difluoride (PVDF) protein blotting membrane with $0.2 \mu \mathrm{m}$ pore size (GE Healthcare Life Sciences). The PVDF membrane was blocked in 5\% non-fat powdered milk in Tris-buffered saline with $0.1 \%$ Tween 20 (or 3\% bovine serum albumin (BSA, Bovogen Biologicals Pty Ltd., Australia) in TBS-T for detection of p-Tyr-1000) at room temperature for $1 \mathrm{~h}$. After a brief rinse with TBS-T, the membrane was incubated overnight at $4{ }^{\circ} \mathrm{C}$ with primary antibodies at 1:1000 dilution. The primary antibody was detected with secondary horseradish peroxidase-conjugated anti-rabbit antibody (Jackson Immune Research, USA) at 1:40000 dilution. The membrane was developed using Amersham ECL Prime Western Blotting Detection Reagent (GE Healthcare Life Sciences, USA), and chemiluminescence was detected using ChemiDoc imaging system (Bio-Rad, USA).

\section{Statistical analysis}

Data were analysed using GraphPad PRISM 4.0 software. Results are expressed as the mean \pm standard error (SEM). One-way ANOVA with posthoc Bonferroni's Multiple Comparison Test were used to examine the statistical significance between means. Differences were considered significant at $P<0.05$.

\section{Results}

NETs induce aggregation, secretion and activation of washed human platelets

We first examined the ability of cell-free NETs to directly induce aggregation of washed human platelets independently of the coagulation pathway. Platelets were washed three times in CGS buffer to remove any contaminating plasma, then resuspended in Tyrode-HEPES buffer (with $1.8 \mathrm{mM}$ calcium chloride). Light transmission aggregometry was used to measure platelet aggregation. Autologous cell-free NETs at different dilutions induced marked platelet aggregation (Fig. 1a). Interestingly, platelet aggregation response was apparent only after 5 mins in the presence of the highest concentration of NETs used (10\% of final reaction volume) (Fig. 1b). For all experiments, it was imperative that NETs were used within the same day of isolation as freezing or storing NETs at $4{ }^{\circ} \mathrm{C}$ for more than $24 \mathrm{~h}$ completely abolished their activity.

As platelet secretion amplifies platelet aggregation, we assessed the ability of NETs to induce platelet dense granule secretion of ATP/ADP using a luminescence assay. NETs triggered significant ATP/ADP secretion from platelet dense granules compared to vehicle control
(Fig. 1c). Platelet secretion was examined after 1 and 10 min incubation with NETs to identify the time required for secretion compared to aggregation. NETs induced significant platelet secretion by $1 \mathrm{~min}$, while aggregation did not occur until 5 min (Fig. 1b-c), indicating that NET-induced platelet secretion precedes aggregation. Furthermore, we also examined if platelet functional response occurred concomitantly with intracellular signalling, particularly the phosphorylation of proteins at tyrosine residues. Indeed, NETs induced tyrosine phosphorylation of several substrates with strong migrating bands at $\sim 134,80$ and $60 \mathrm{kDa}$ compared to vehicle control (Fig. 1d).

\section{NETs induce surface expression of receptors and phosphatidyl serine exposure on platelets}

We also examined $\alpha$-granule secretion by measuring the surface expression of P-selectin. Platelets incubated with NETs for 10 to 15 min showed a significant increase of P-selectin surface expression as detected by flow cytometry (Fig. 2a-b). A conformational change in platelet $\alpha \operatorname{IIb} \beta 3$ receptor is required for platelet aggregation [27]. Therefore we assessed platelet surface expression of active-form $\alpha \operatorname{IIb} \beta 3$ using PAC1 monoclonal antibody. As shown in Fig. 2a-b, NETs induced a conformational change of $\alpha \operatorname{IIb} \beta 3$ from resting to an activated state. As PS exposure on platelets can propagate coagulation [28], we assessed the ability of NETs to induce PS exposure on the platelet surface. Platelets were incubated with NETs for $30 \mathrm{~min}$ at $37{ }^{\circ} \mathrm{C}$ with continuous stirring at $1200 \mathrm{rpm}$ before analysing PS expression. Annexin V-FITC was used to stain PS and was analysed by flow cytometry. NETs induced a marked increase in PS expression on platelet's surface (Fig. 2c-d), suggesting that NET-activated platelets can provide a procoagulant surface.

\section{The role of NET-derived DNA, histones, cat G, and MPO in NET-induced platelet response}

As the major components of NETs are DNA and histones, we first investigated whether the effect of NETs on washed platelets is mediated via NET-derived DNA and/or histones. DNA-histone complexes were confirmed in cell-free NETs using Cell Detection ELISA PLUS kit. Based on comparisons between whole neutrophil lysates and NET dilution samples, the concentration of DNA-histone complex in cell-free NETs used in majority of experiments (i.e. $10 \%$ final NETs) was equivalent to the amount present in approximately $3.8 \pm 1.2 \times 10^{6} / \mathrm{mL}$ of neutrophil lysate (Additional file 1: Figure S1). Additionally, the $10 \%$ cell-free NET solution was determined to contain $292 \pm 172 \mathrm{pg} / \mathrm{mL}$ of elastase, another major protein component of NETs (Additional file 1: Figure S2). 

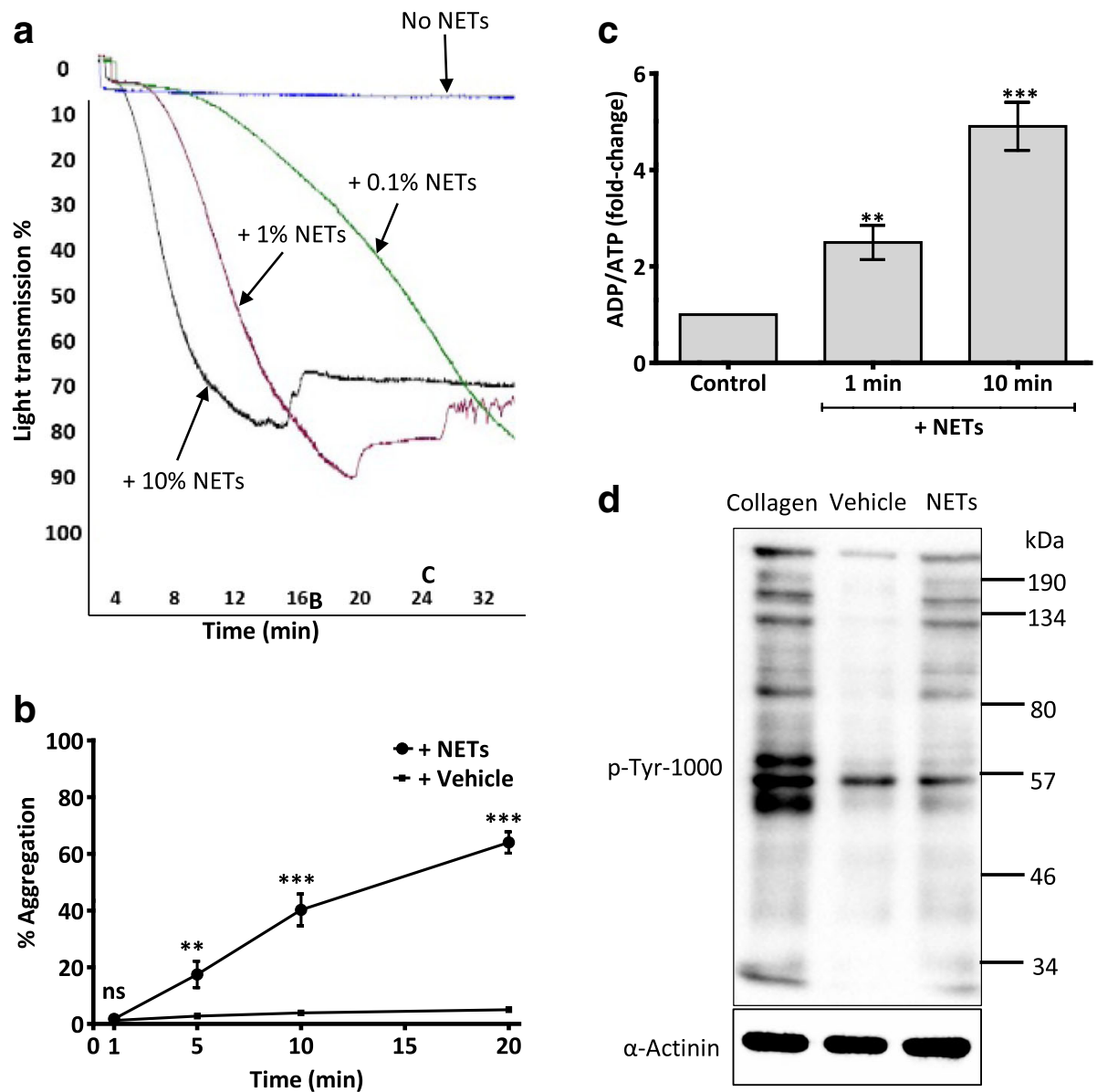

Fig. 1 NETs directly induce aggregation of washed human platelets. a Representative traces showing dose-dependent aggregation of washed human platelets (WP, $3 \times 10^{8} / \mathrm{mL}$ ) in response to cell free-NETs. $0.1,1$ and $10 \%$ NETs refers to NETs constituting $0.1,1$ or $10 \%$ of final reaction volume, respectively (e.g. 10\% NET is 1-volume NET solution to 9-volume platelets). Platelet aggregation was measured by light transmission aggregometer (Chrono-log). NETs were used at $10 \%$ of final reaction volume for following experiments*. b Progress time curve displaying $\%$ of NET-induced platelet aggregation which steadily increased over 20 min. c ATP/ADP release from NET-stimulated platelets. WP $\left(1 \times 10^{8} / \mathrm{mL}\right)$ were incubated with NETs with a gentle shake at $37^{\circ} \mathrm{C}$ for 1 and $10 \mathrm{~min}$ before adding Chrono-Lume reagent. Luminescence was measured using Enspire Multimode Plate Reader (PerkinElmer). NETs induced significant ATP/ADP secretion from platelets at 1 and 10 min. Results represent fold change in luminescence arbitrary absorbance unit relative to vehicle (PBS) control. Data expressed as mean $\pm \mathrm{SEM} ;{ }^{* *} P<0.01,{ }^{* * *} P<0.0001, N \geq 5$. d Platelet signalling in response to NETs was examined by Western blot analysis. WP $\left(3 \times 10^{8} / \mathrm{mL}\right)$ were incubated with collagen $(5 \mu \mathrm{g} / \mathrm{mL})$, vehicle (PBS) or NETs for 3 min. Twenty $\mu$ l of total cell lysate was analysed by sodium dodecyl sulphate-polyacrylamide gel electrophoresis and immunoblotted for phospho-Tyrosine (p-Tyr-1000). Equal loading was verified by a-actinin. Western blots indicate tyrosine-phosphorylated proteins in NET-stimulated platelets. ${ }^{*} 10 \%$ NET solution is prepared from $1 \times 10^{7} / \mathrm{ml}$ of PMA-activated neutrophils, however due to losses during preparation steps, $10 \%$ NET is estimated to contain histone/DNA complexes equivalent to $3.8 \pm 1.2 \times 10^{6} / \mathrm{mL}$ neutrophils (Additional file 1: Figure S1). The elastase content present in a $10 \%$ NET reaction volume is $292 \pm 172 \mathrm{pg} / \mathrm{mL}$

Calf thymus histones $(\mathrm{CTH})$ are well-established platelet agonists [29] and were used as a positive control. CTH $(1,5,20$ and $40 \mu \mathrm{g} / \mathrm{mL})$ induced a dose-dependent aggregation of washed human platelet (Fig. 3a). Heparin can strongly bind to and abate the effect of histones on platelets [30-32]. Indeed, heparin $20 \mathrm{U} / \mathrm{mL}$ completely abated CTH but not NET-induced platelet aggregation (Fig. 3 b, d). Collagen $(5 \mu \mathrm{g} / \mathrm{mL})$ was added to the CTH-heparin reaction in order to verify that the platelet functional response to another agonist remained unaffected (Fig. $3 b)$.

In order to test the impact of DNA on NET-induced platelet aggregation, NETs were pre-treated with DNase $(20,200 \mathrm{U} / \mathrm{mL})$ for $30 \mathrm{~min}$ at $37{ }^{\circ} \mathrm{C}$ before adding to platelets (where NETs was used at $10 \%$ of the final reaction volume). DNase can dismantle NET-DNA (Additional file 1: Figure 3). However, DNase did not reduce the ability of NETs to induce aggregation of washed human platelets (Fig. 3c \& d), suggesting neither DNA nor 

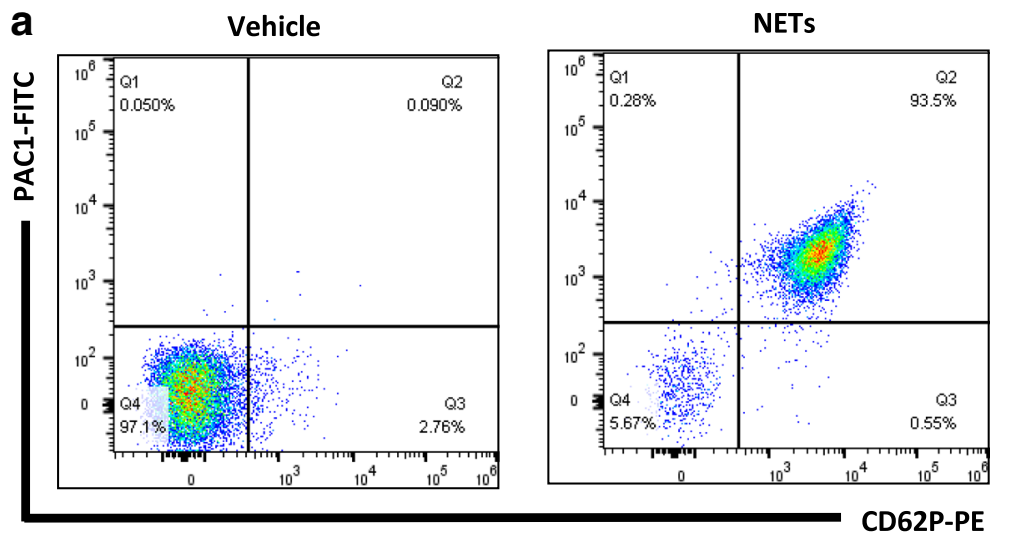

b
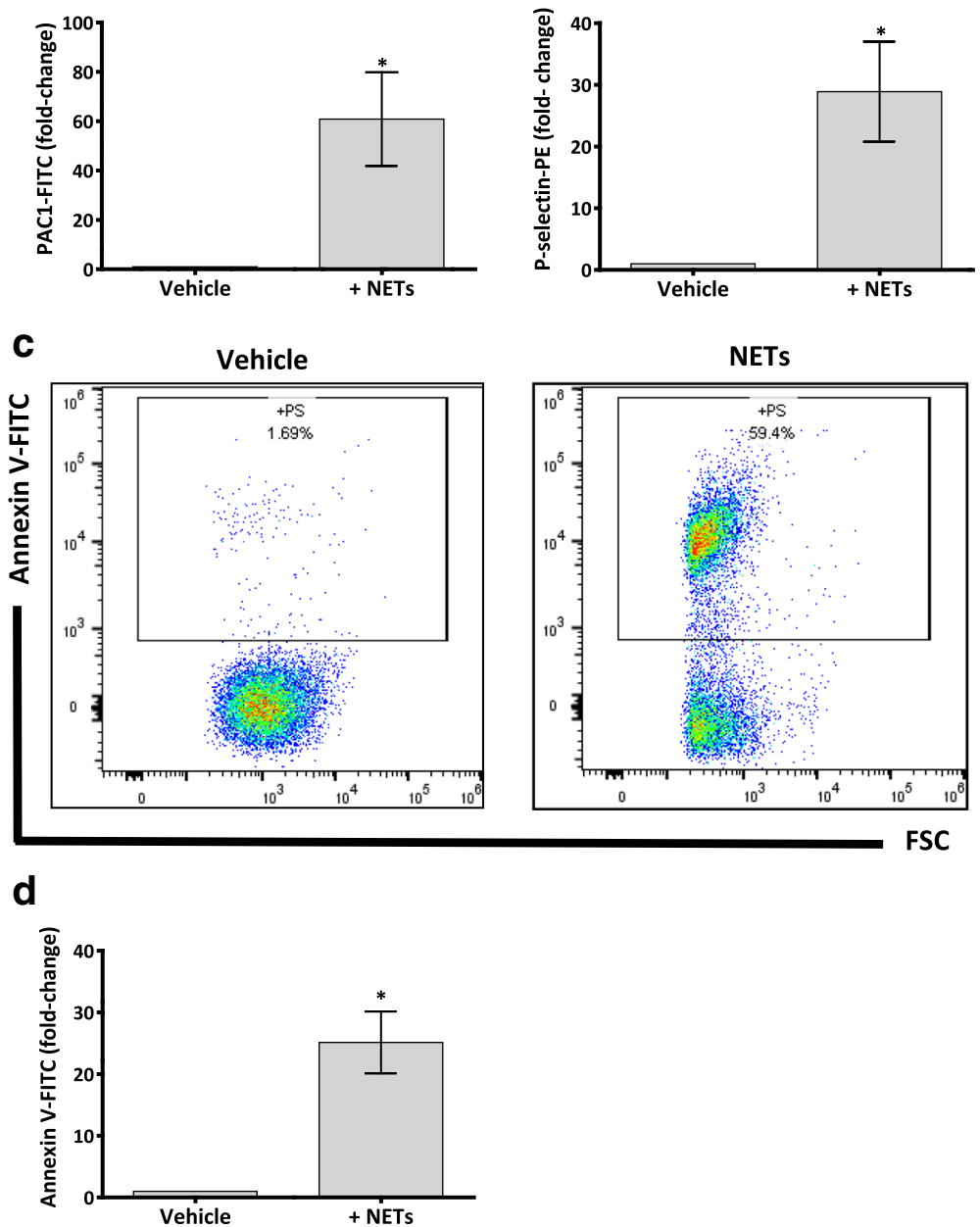

Fig. 2 NETs induce platelet activation and phosphatidyl serine (PS) exposure on washed human platelets. a Representative dot plot of CD62P (P-selectin), PAC1 (active-form allbß3) fluorescence. WP $\left(1 \times 10^{8} / \mathrm{mL}\right)$ were treated with vehicle (PBS) or NETs then incubated with labelled monoclonal antibodies phycoerythrin (PE)-conjugated CD62P and fluorescein isothiocyanate (FITC)-PAC1 for 10-15 min in the dark. The reaction was stopped by fixing cells in 2\% paraformaldehyde before analysing samples with flow cytometry (BD LSRFortessa ${ }^{\mathrm{TM}}$ cell analyzer). NETs induced expression of P-selectin and active-form allb $\beta 3$. $\mathbf{b}$ Fold change in the geometrical mean fluorescence of P-selectin-PE and PAC1-FITC in NET-activated platelets compared to vehicle-treated platelets. c WP $\left(3 \times 10^{8} / \mathrm{mL}\right.$ ) were incubated with vehicle (PBS) or NETs for 30 min at $37^{\circ} \mathrm{C}$ with continuous stirring at $1200 \mathrm{rpm}$. PS was detected by incubating platelets with Annexin V-FITC in binding buffer for $15 \mathrm{~min}$ in the dark. Samples were then washed in binding buffer and analysed by flow cytometry (BD LSRFortessa). NETs induced PS exposure compared to vehicle control. $\mathbf{d}$ Fold change in geometrical mean of fluorescence of Annexin V-FITC in NET-activated platelets compared to vehicle-treated platelets. In all assays, NETs constituted $10 \%$ of final reaction volume and contains $292 \pm 172 \mathrm{pg} / \mathrm{mL}$ of NET-elastase. Data are expressed as mean $\pm \mathrm{SEM}^{*} P<0.05, n \geq 4$ 

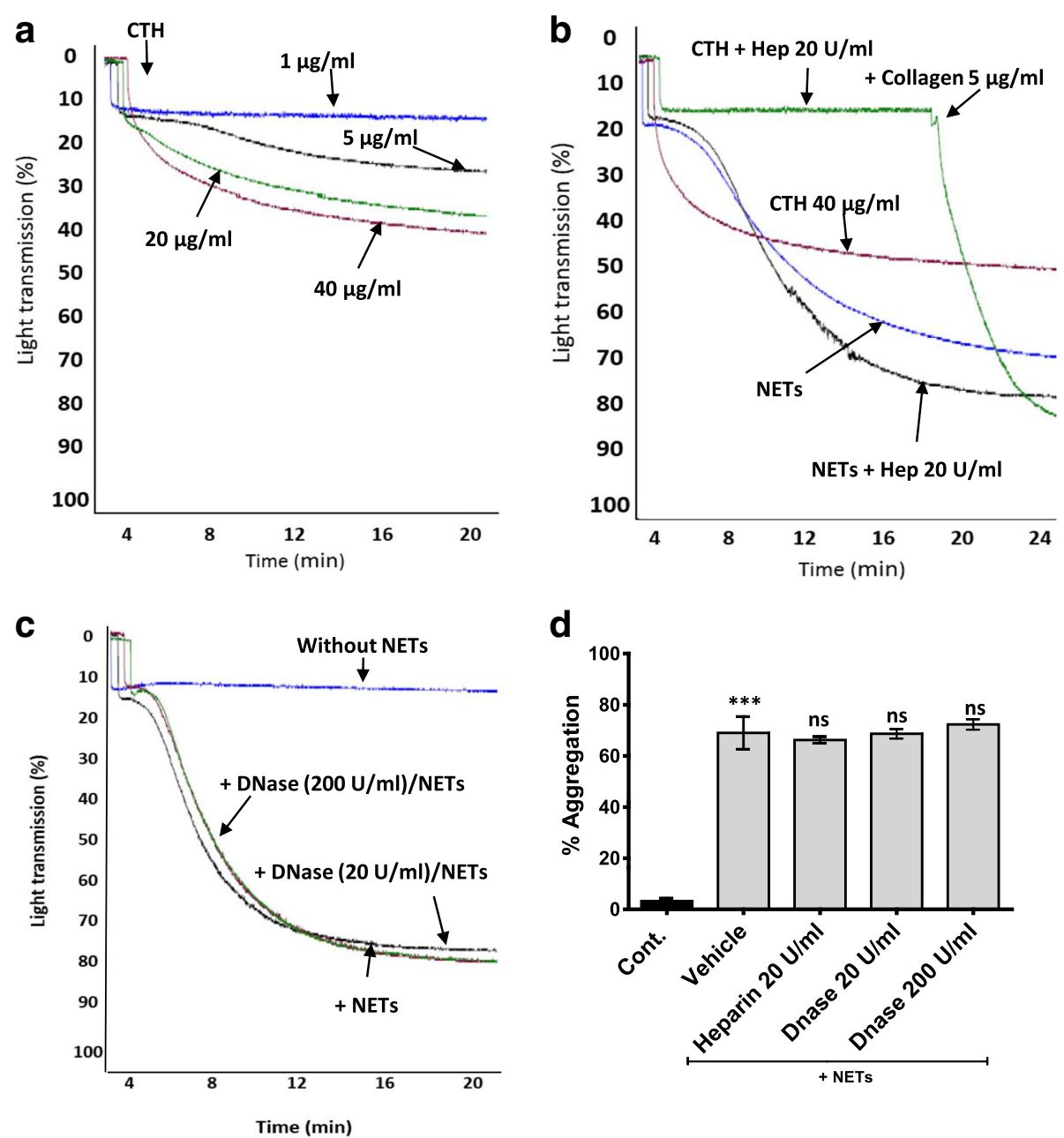

Fig. 3 Heparin and DNase did not reduce NET-induced platelet aggregation. a Representative traces showing dose-dependent aggregation of washed human platelets (WP, $3 \times 10^{8} / \mathrm{mL}$ ) in response to calf thymus histones $(\mathrm{CTH} ; 1,5,20$ and $40 \mu \mathrm{g} / \mathrm{mL})$. b Representative aggregation traces showing the effect of heparin on NET and CTH-induced platelet aggregation. The reactions were allowed to proceed for 18 min, then collagen $(5 \mathrm{gg} / \mathrm{mL})$ was added to the $\mathrm{CTH}$-Heparin reaction to test platelet functional response. c Representative aggregation traces showing the effect of DNase on NET-induced platelet aggregation. NETs were pre-treated with DNase $(20,200 \mathrm{U} / \mathrm{mL})$ for $30 \mathrm{~min}$ at $37^{\circ} \mathrm{C}$ before addition to WP $(3 \times$ $10^{8} / \mathrm{mL}$ ). Traces are representative of 3 independent experiments. $\mathbf{d}$ Bar graphs depict $\%$ of platelet aggregation treated with NET alone or with Heparin and DNase. Percentage platelet aggregation was measured at $20 \mathrm{~min}$. In all assays, NETs constituted 10\% of final reaction volume and contains $292 \pm 172 \mathrm{pg} / \mathrm{mL}$ of NET-elastase. Data are expressed as mean $\pm S E M,{ }^{*} P<.05$; ns: non-significant, $n \geq 3$

histones are major contributors to NET-induced washed platelet aggregation. Since histones can activate platelets, which has suggested to be mediated through toll-like receptor (TLR) 2 and TLR4 [18], platelets were pre-incubated with TLR2- and TLR4-blocking antibodies or matching isotype controls $(50 \mu \mathrm{g} / \mathrm{mL})$ for $15 \mathrm{~min}$ before incubation with NETs. Similarly, anti-TLR2 and -TLR4 antibodies also did not affect NET-induced platelet activation (Additional file 1: Figure S4). It was recently reported that calf thymus histones can activate platelets through GPVI receptor [29]. However, pre-incubating platelets with a GPVI inhibitor, losartan (30 $\mu \mathrm{M}$ [33-35]) did not affect NET-induced platelet aggregation (Additional file 1: Figure S5). Our data suggest that neither DNA nor histones contribute to NET-induced washed platelet aggregation or activation.

Extracellular DNA and histones gained considerable interest for their contribution to NET-induced thrombosis, while little attention has been paid to other components of NETs such as neutrophil proteases. Previous studies have reported that Cat G and MPO can modulate platelet response $[36,37]$. To determine the effect of NET-derived Cat G and MPO on platelet activation, we used Cat G and MPO inhibitors at concentrations previously described in the literature [36, 37]. Although Cat $G$ inhibition did not significantly affect the maximum aggregation response of platelet to NETs, we observed a trend of increased aggregation lag time (data not 
shown). Interestingly, Cat G inhibitor (Cat G I) but not MPO inhibitor (MPO I) significantly reduced NET-induced platelet expression of P-selectin (\% Max response: 100 vs. $85 \pm 3.2$; $\left.{ }^{*} P<0.05, n=4\right)$, PAC1 (\% Max response: 100 vs. $77.3 \pm 3.7 ;{ }^{*} P<0.05, \mathrm{n}=4$ ) and PS exposure (\% Max response: 100 vs. $64.6 \pm 12.1$; ${ }^{*} P<0.05$, $n=4)$ (Fig. 4a-c). The concentration of Cat G I used $(0.5 \mu \mathrm{M})$ did not affect platelet physiological response to thrombin $(0.1 \mathrm{U} / \mathrm{mL})$ (Additional file 1: Figure S6), confirming that the inhibitory response is specific to NET-bound Cat G activation of platelets. Additionally, similarly to MPO, neutrophil elastase did not markedly affect NET-induced platelet activation (Additional file 1: Figure S7).

\section{SYK and NOX1 contribute to NET-induced platelet response}

We began to delineate the platelet receptors and downstream pathway involved in NET-induced platelet activation. The non-receptor tyrosine kinase Syk mediates signalling from major platelet receptors, including the histone receptors GPVI and TLR2 [29]. Whereas NADPH oxidase (NOX) regulates GPVI-induced reactive oxygen species generation and subsequent thromboxane A2 (TxA2) production [38]. We demonstrate that platelet Syk phosphorylation was augmented upon exposure to NETs, which was accompanied by upregulation of the downstream signalling molecules p-Akt and p-Erk1/2 (Fig.5e). A Syk phosphorylation inhibitor (Bay $61-3606,5 \mu \mathrm{M})$ reduced NET-induced platelet aggregation (\% Max Agg: 100 vs. $74.21 \pm 8.8$; ${ }^{* * *} P<0.001, n=7$ ) (Fig. 5b), dense granule secretion (\% Max secretion at $1 \mathrm{~min}: 100$ vs. $52.2 \pm 9.2$, ${ }^{* * *} P<0.001$; at $10 \mathrm{~min}: 100$ vs. $64.4 \pm 6.3$; ${ }^{* *} P<0.01, n=6$ ) (Fig. 5e-f), and PAC1 expression (\% Max response: 100 vs. $81.7 \pm 6.9$; ${ }^{*} P<0.05, n=3$ ) (Fig. 5c), while P-selectin expression remained unchanged (Fig. 5d). On the other hand, NOX1 inhibitor (ML171, $5 \mu \mathrm{M}$ ) did not alter NET-induced platelet aggregation or activation (P-selectin and active-form $\alpha \operatorname{IIb} \beta 3$ expression) (Fig. 5a-d), however, it significantly reduced NET-induced platelet dense granule secretion (\% Max secretion at 1 min: 100 vs. $62.4 \pm 7.1$; ${ }^{* *} P<0.01$; at $10 \mathrm{~min}: 100$ vs. $58.6 \pm 6.6$; ${ }^{* *} P<0.01, n=6$ ) (Fig. 5 d). Collectively, these results highlight the diversity of platelet pathways that are activated by NETs.

\section{$\mathrm{P}_{2} \mathrm{Y}_{12}$ but not cyclooxygenase pathway is required for NET-induced platelet aggregation}

Drugs that target either $\mathrm{P}^{2} \mathrm{Y}_{12}$ (e.g., ticagrelor) or cyclooxygenase pathway (aspirin) are clinically available and crucial in the management of thrombosis [39]. Therefore, we were interested in investigating their effect on NET-induced platelet response. Ticagrelor markedly reduced NET-induced platelet aggregation (\% Max Agg:
100 vs. $56 \pm 10.1 ; * * 0<0.001, n=5$ ) (Fig. $6 \mathrm{~b}$ ), dense granule secretion (\% Max secretion; at 1 min: 100 vs. 69.3 $\pm 9.8 ; P=0.052$; at $10 \mathrm{~min}: 100$ vs. $62.1 \pm 9.4 ;{ }^{*} P<$ $0.05, n=5)$ (Fig. 6e-f), and expression of P-selectin (\% Max response: 100 vs. $72.9 \pm 2.9$; **** $P<0.001, n=3$ ) (Fig. $6 \mathrm{~d}$ ) and PAC1 (\% Max response: 100 vs. $40.34 \pm 11$; ${ }^{* * * * P} \mathrm{P}$ $<0.001, \mathrm{n}=3$ ) (Fig. 6c). Surprisingly, aspirin did not alter NET-induced platelet aggregation or expression of P-selectin and PAC1 (Fig. 6b-d, Additional file 1: Figure S8), however it significantly reduced NET-induced platelet dense granule secretion (\% Max secretion; at $1 \mathrm{~min}$ : 100 vs. $62.6 \pm 7.8 ; * P<0.01, n=5$; at $10 \mathrm{~min}: 100$ vs. $63.5 \pm 13.1 ; * P<0.05, n=5$ ) (Fig. 6e-f). These findings suggest a broader role of ticagrelor, but not aspirin, in reducing NET-induced platelet response.

\section{NET-induced platelet response is dependent on integrin allb $\beta 3$}

Considering the role of NETs in mediating platelet adhesion and spreading [30], we were interested in examining the effect of platelet adhesion receptor $\alpha \operatorname{IIb} \beta 3$ in NET-induced platelet response. Reopro, a monoclonal antibody that binds to and inhibits the active form of $\alpha I I b \beta 3$, dramatically reduced NET-induced platelet aggregation (\% Max Agg: 100 vs. $31.2 \pm 3.3$; ${ }^{* * *} P<0.001, n$ $=4)$ (Fig. 7b) and dense granule secretion (\% Max secretion; at $1 \mathrm{~min}$ : 100 vs. $50 \pm 12.2 ; P=0.075$; at $10 \mathrm{~min}$ : 100 vs. $59.1 \pm 10.8$; ${ }^{*} P<0.05, n=5$ ) (Fig. 7 e-f). Moreover, Reopro completely inhibited NET-induced PAC1 expression (Fig. 7c), most likely due to competitive binding to $\alpha I I b \beta 3$ which is also the target for the PAC1 antibody. However, Reopro did not reduce NET-induced platelet P-selectin expression (Fig. 7d), suggesting that NETs do not trigger $\alpha \operatorname{IIb} \beta 3$ outside-in signalling in platelets.

RGDS $(100 \mu \mathrm{M})$, a peptide that binds to $\alpha \operatorname{IIb} \beta 3$ and prevents conformational change triggered by inside-out signalling, significantly reduced NET-induced platelet aggregation (\% Max Agg: 100 vs. $43.7 \pm 5.6$; ${ }^{* * *} P<0.001$, $n=3$ ) (Fig. 7b) and dense granule secretion (\% Max secretion; at $1 \mathrm{~min}: 100$ vs. $66 \pm 8.7$; ${ }^{*} P<0.05$; at $10 \mathrm{~min}$ : 100 vs. $48.2 \pm 13.8$; ${ }^{* *} P<0.01, n=5$ ) (Fig. $7 \mathrm{e}-\mathrm{f}$ ). Platelet activation show that RGDS markedly reduced NET-induced platelet P-selectin expression (\% Max response: 100 vs. $82.6 \pm 3.7$; ${ }^{* *} P<0.01, n=3$ ) (Fig. 7 d) and PAC1 expression (\% Max response: 100 vs. $38.4 \pm 16.2$; $* * P<0.01, n=3$ ) (Fig. 7c). Overall, our results confirm the crucial role of $\alpha \operatorname{IIb} \beta 3$ in NET-induced platelet response.

\section{Discussion}

Our study explored the effect of in vitro-generated NETs on washed human platelets. As described in the methods, cell-free NETs were isolated from PMA-activated human neutrophils. PMA is a known 


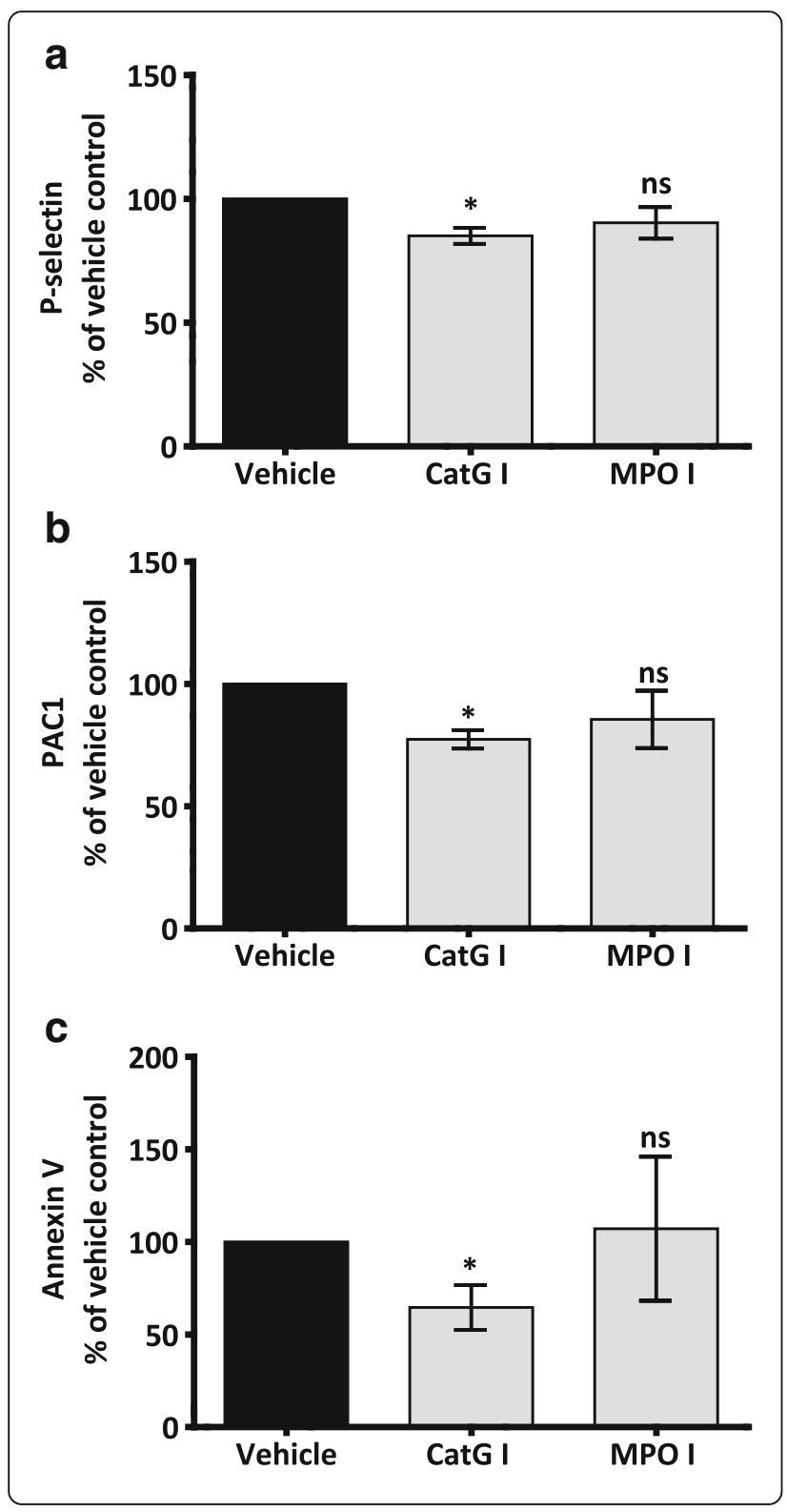

Fig. 4 Inhibition of Cat G, but not MPO, attenuates NET-induced platelet response. Flow cytometry analysis of P-selectin, PAC1, and PS exposure on platelets. NETs were pre-treated with vehicle or inhibitors for $30 \mathrm{~min}$ at $37^{\circ} \mathrm{C}$. a-b WP $\left(1 \times 10^{8} / \mathrm{mL}\right)$ were incubated with NETs pre-treated with vehicle (0.1\% DMSO in PBS), Cat G I $(0.5 \mu \mathrm{M})$ or MPO I $(50 \mu \mathrm{M})$ for $10-15$ min in the dark with labelled monoclonal antibodies that detect P-selectin (CD62P) and active allbB3 (PAC1). The reaction was stopped by fixing cells in 2\% PFA before analysing samples with flow cytometry (BD LSRFortessa). Bar graphs depict the \% inhibition in P-selectin, and active allb $\beta 3$ expression in platelets treated with NETs pre-treated with different inhibitors compared to platelets treated with NETs that were pretreated with vehicle. Results were normalized for each donor relative to NET-induced platelet response. c WP $\left(3 \times 10^{8} / \mathrm{mL}\right)$ were incubated with NETs pre-treated with vehicle (0.1\% DMSO in PBS), Cat G I $(0.5 \mu \mathrm{M})$ or $\mathrm{MPO}$ I $(50 \mu \mathrm{M})$ for $30 \mathrm{~min}$ at $37^{\circ} \mathrm{C}$ with continuous stirring at $1200 \mathrm{rpm}$. Platelets were then stained with Annexin V-FITC in binding buffer for $15 \mathrm{~min}$ in the dark. Samples were then washed in binding buffer and analysed by flow cytometry (BD LSRFortessa). Bar graph depicts the \% inhibition in PS expression in platelets treated with NETs pre-treated with different inhibitors compared to platelets treated with NETs pre-treated with vehicle. Results were normalised for each donor relative to NET-induced platelet response. In all assays, NETs constituted 10\% of final reaction volume and contains $292 \pm 172 \mathrm{pg} / \mathrm{mL}$ of NET-elastase. Data are expressed as mean \pm SEM, ${ }^{*} P<.05 ;$ ns: non-significant, $n=4$

platelet agonist [40], however PMA was washed out with the culture media after $3 \mathrm{~h}$ incubation with neutrophils, thus it is highly unlikely that NET-induced platelet aggregation was confounded by PMA. Unlike the widely used method of cell-free NET preparation by Urban et al., [26], we did not use this method involving DNase/ EDTA, as EDTA can hinder platelet functional response [41]. We demonstrate that intact cell-free NETs exhibit the capacity to directly activate several platelet responses, such as aggregation, dense and $\alpha$-granule secretion (ADP release and P-selectin expression), PS exposure and activation of integrin $\alpha \operatorname{IIb} \beta 3$, which occurred independently of the presence of coagulation factors or thrombin. NETs triggered a dose-dependent aggregation response in platelets with delayed lag time which correlates with the ability of NETs to first induce rapid platelet dense granule secretion.

In addition to being a procoagulant platform, NETs induced PS exposure on platelet's surface, a characteristic feature of procoagulant platelets. In the presence of small amounts of activated coagulation factors, PS can instigate thrombin generation, which can directly activate platelets and conversion of fibrinogen to fibrin [42]. In washed platelets, strong or multiple agonists can trigger PS-exposing procoagulant platelets [43, 44]. The latter is in line with our data and suggests that NETs are not a single agonist but a platform that presents a number of agonists that can promote platelet activation via multiple pathways. 

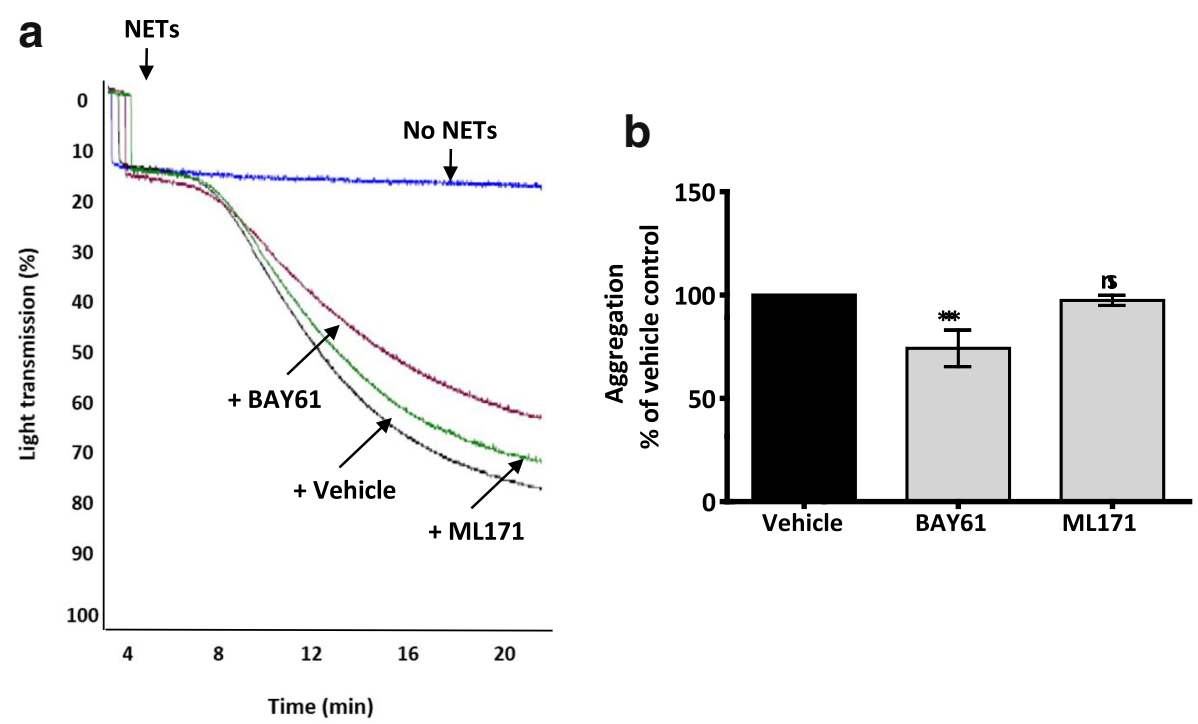

C

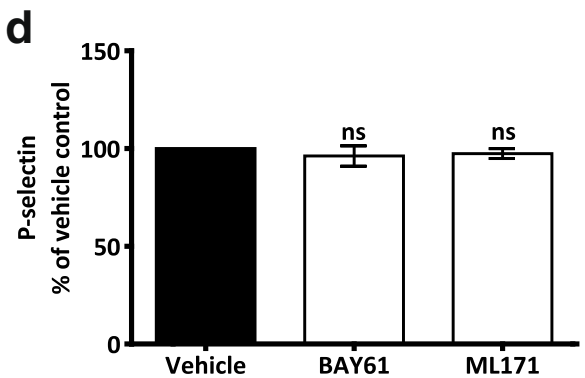

e

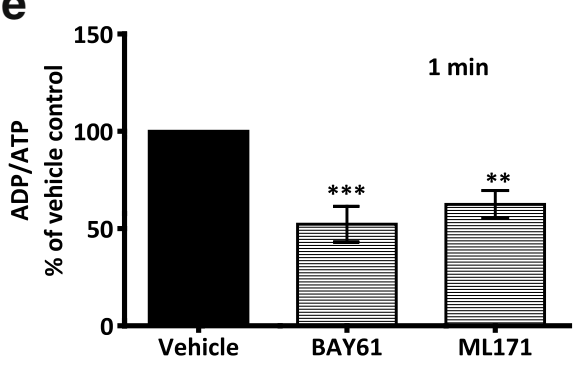

f

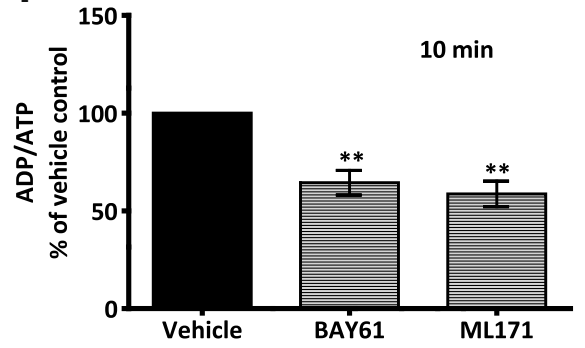

e

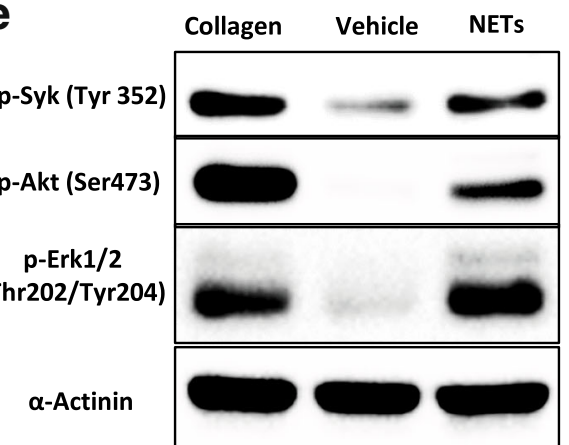

Fig. 5 (See legend on next page.) 
(See figure on previous page.)

Fig. 5 Syk, but not NOX1, inhibition attenuated NET-induced platelet aggregation. a Representative aggregation traces showing the effect of Syk phosphorylation (BAY61, $5 \mu \mathrm{M})$ and NOX1 (ML171, $5 \mu \mathrm{M})$ inhibitors on NET-induced platelet aggregation. WP $\left(3 \times 10^{8} / \mathrm{mL}\right)$ were pre-incubated with the inhibitors for $15 \mathrm{~min}$ at $37^{\circ} \mathrm{C}$ before addition of NETs. Platelet aggregation was measured using transmission aggregometer (Chronolog). $\mathbf{b}$ Bar graph comparing the effect of BAY61 and ML171 on NET-induced platelet aggregation. Platelet aggregation percentage was calculated after 20 min on a light transmission aggregometer. Results were normalized for each donor relative to NET-induced platelet aggregation. Data are expressed as mean \pm SEM, ${ }^{* * *} P<.001$; ns: non-significant, $n=7$. (c-d) Bar graphs comparing the effect of BAY61 (5 $\left.\mu M\right)$ and ML171 (5 $\mu \mathrm{M})$ on platelet activation (measured by P-selectin and active allb $\beta 3$ expression, $n=3$ ) and (e-f) ATP/ADP secretion $(n=6)$ elicited by NETs. Results were normalized for each donor relative to NET-induced platelet response. Data are expressed as mean \pm SEM, ${ }^{*} P<0.05$, ${ }^{* *} P<0.01$, ${ }^{* * *} P<0.001$, ns: non-significant. e Syk phosphorylation is augmented by NETs. WP $\left(3 \times 10^{8} / \mathrm{mL}\right)$ were incubated with collagen $(5 \mu \mathrm{g} / \mathrm{mL})$, vehicle (PBS) or NETs for $3 \mathrm{~min}$. Forty-five $\mu \mathrm{l}$ of total cell lysate was then analysed by sodium dodecyl sulphate-polyacrylamide gel electrophoresis and immunoblotted for p-Syk, p-Akt and p-Erk1/2. Equal loading was verified by a-actinin. In all assays, NETs constituted 10\% of final reaction volume and contains $292 \pm 172 \mathrm{pg} / \mathrm{mL}$ of NET-elastase. The immunoblots are representative sample of 3 independent experiments

NETs are made up of DNA and proteins (1:1.67 \pm $0.26 \mathrm{~g}$, DNA to proteins) [26]. Histones account for $70 \%$ of all NET-associated proteins [18, 26, 29, 45]. Previous studies showed the ability of single-strand DNA to bind platelets [46] while double strand DNA can induce platelet aggregation $[47,48]$. Degradation of DNA with DNase has been shown to digest NETs and reduce platelet aggregates under flow [30], or platelet adhesion to NETs under static condition [12]. On the other hand, histones are well-established as platelet agonists that can trigger a cascade of platelet responses with defined surface receptors and signalling pathways [18, 29, 45]. Heparin has been reported to bind to histones, thus preventing its binding to platelets [19, 32]. Surprisingly, in this study DNase- and heparin-treated NETs were still capable of aggregating washed platelets and induced expression of P-selectin and active $\alpha \operatorname{IIb} \beta 3$ to the same extent of untreated NETs. Although DNase and heparin can destabilise the NET structure [9], the presence of freely suspended individual NET components - such as cell free-DNA, histones, and neutrophil proteases - may have greater capacity and exposure to directly bind and activate platelets, as opposed to being restricted on NETs. This presumption is in line with a study that showed DNAse-treatment of NETs resulted in increased coagulation effect [15]. Moreover, nuclear histones have different molecular mass and stoichiometry compared to NET-derived histones [26]. Therefore they may exhibit different biological activity. Indeed, a recent report has found that individual histones and DNA capable of inducing coagulation, but not intact NETs that were released from human neutrophils [49].

Histones are known to induce platelet Syk kinase activation through GPVI, and other tyrosine kinase-linked receptors [29]. We show that inhibition of Syk attenuated NET-induced platelet responses. However, inhibitors of histone receptors on platelets (TLR2, TLR4 and GPVI) did not reduce NET-induced platelet aggregation. Moreover, the sheer magnitude of platelet aggregation response to NETs in washed system precludes a significant contribution of histones which are known to have a tenfold lower platelet aggregation response in washed platelets compared to PRP [29].

Neutrophil granular proteins are a part of NETs and have separately been shown to activate platelets $[37,50]$. Neutrophil serine proteases and histones are negatively charged proteins [51] and would be tightly bound to the positively charged DNA backbone of NETs, thus most likely remain bound after isolation procedures [26]. The pre-treatment of NETs with an MPO inhibitor did not significantly reduce NET-induced upregulation of P-selectin, active $\alpha \operatorname{IIb} \beta 3$, or PS exposure on platelets, suggesting MPO does not play a major role in NET-induced platelet activation which is consistent with previous studies reporting that MPO is not a robust activator of platelets, but only induces partial activation or priming of platelets [37]. On the other hand, inhibiting Cat G resulted in a significant decrease in platelet surface expression of P-selectin, active $\alpha \operatorname{IIb} \beta 3$ and PS. This suggests Cat G as a molecular mediator of NET-induced platelet activation, and potentially significant contributor to thrombus formation, as previously described [36]. NE is the second most abundant NET-associated proteins after histones [26] and can potentiate Cat G-induced platelet aggregation [52], however in our hands, NE inhibitor did not affect NET-induced platelet responses (data not shown).

As the NET scaffold contains an array of associated proteins, some of which have been independently associated with platelet activation [26, 36, 37, 50, 52-54], a single inhibitor is highly unlikely to completely abrogate NET-induced platelet responses. However, we were interested mainly in clarifying the major NET components, platelet receptors and downstream signalling molecules that mediate NET-induced platelet secretion and aggregation. Inhibition of the tyrosine kinase Syk activity, $\mathrm{P}_{2} \mathrm{Y}_{12}$ and $\alpha \mathrm{IIb} \beta 3$ reduced NET-induced platelet aggregation and secretion. While inhibition of NOX1 and TxA2 reduced NET-induced platelet dense granule secretion, but not aggregation.

The role of NETs in initiating thrombosis in vivo has been established in mice models of different diseases [55]. However, the molecular mechanisms that drive 

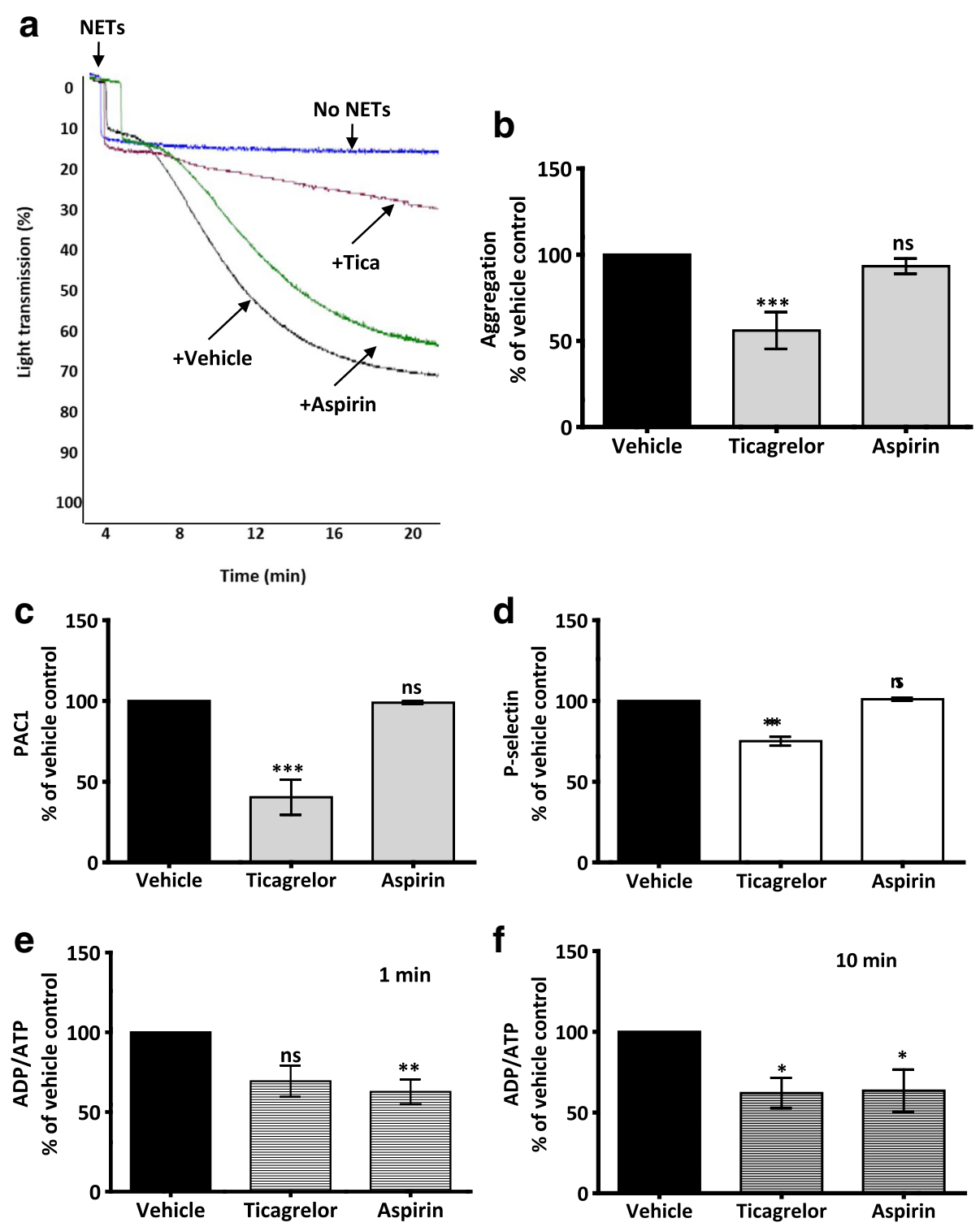

Fig. 6 Inhibition of cyclooxygenase pathway in platelets attenuated NET-induced platelet secretion but not aggregation, while inhibition of P2Y 12 affects both. a Representative aggregation traces showing the effect of ticagrelor $(1 \mu \mathrm{M})$ and aspirin $(100 \mu \mathrm{M})$ on NET-induced platelet aggregation. WP $\left(3 \times 10^{8} / \mathrm{mL}\right)$ were pre-incubated with the inhibitors for $15 \mathrm{~min}$ at $37^{\circ} \mathrm{C}$ before addition of NETs. Platelet aggregation was measured by light transmission aggregometry (Chrono-log). b Bar graph comparing the effect of ticagrelor (1 $\mu \mathrm{M})$ and aspirin (100 $\mu \mathrm{M})$ on NETinduced platelet aggregation. Platelet aggregation percentage was calculated after 20 min on a light transmission aggregometer. Results were normalized for each donor relative to NET-induced platelet aggregation. Data are expressed as mean $\pm \mathrm{SEM}$, *** $p<.001 ; \mathrm{ns}$ : non-significant, $n=3$. (c-d) Bar graphs comparing the effect of ticagrelor $(1 \mu \mathrm{M})$ and aspirin $(100 \mu \mathrm{M})$ on platelet activation (measured by P-selectin and active allb $\beta 3$ expression) ( $n=3)$ and (e-f) ATP/ADP secretion $(n=5)$ elicited by NETs. In all assays, NETs constituted $10 \%$ of final reaction volume and contains $292 \pm 172 \mathrm{pg} / \mathrm{mL}$ of NET-elastase. Results were normalized for each donor relative to NET-induced platelet response. Data are expressed as mean \pm SEM, ${ }^{*} P<0.05 ;{ }^{* *} P<0.01 ;{ }^{* *} P<0.001$, ns: non-significant

NET-induced thrombosis are not well understood. As the recent study by Noubouossie et al., has demonstrated that intact NETs do not directly initiate coagulation [49], we propose that platelets but not coagulation factors are more likely to be the main target of NETs in thrombosis. Our study did not account for the disrupting effect of NETs on endothelium which can also initiate thrombosis [56, 57]. We propose that platelets adhere mainly to NET-derived DNA, then multiple NET-bound proteins induce platelet aggregation and PS exposure which then can propagate coagulation and thrombin generation. In addition to their pivotal role in thrombosis, platelets can also orchestrate inflammation [58]. Therefore, although dismantling NETs may reduce 

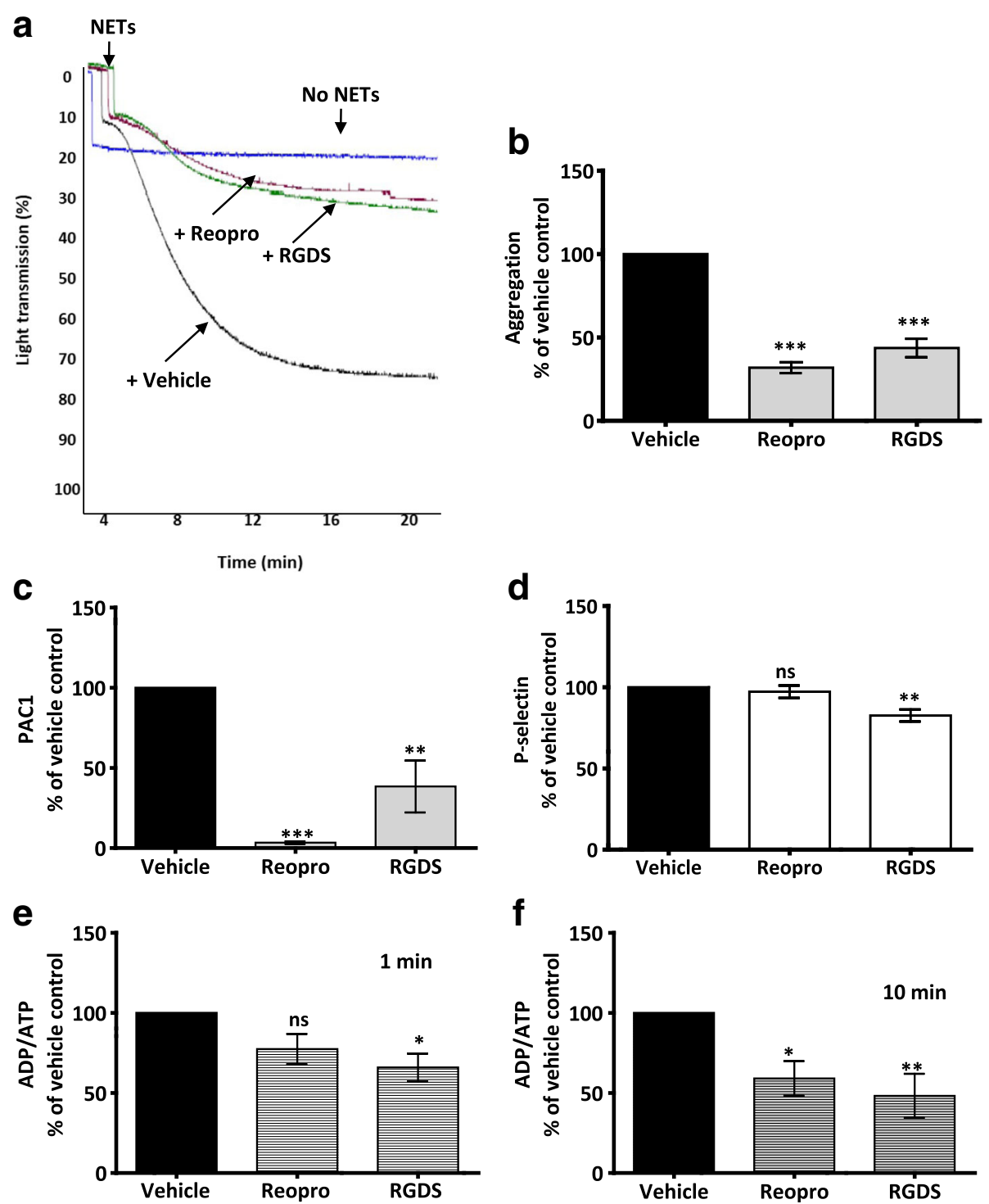

Fig. 7 Inhibition of allb $\beta 3$ attenuates NET-induced platelet response. a Representative aggregation traces showing the effect of Reopro (25 $\mu \mathrm{g} /$ $\mathrm{mL})$ and RGDS $(100 \mu \mathrm{M})$ on NET-induced platelet aggregation. WP $\left(3 \times 10^{8} / \mathrm{mL}\right)$ were pre-incubated with the inhibitors for 15 min at $37^{\circ} \mathrm{C}$ before addition of NETs. Both Reopro and RGDS reduced platelet aggregation. Platelet aggregation was measured by light transmission aggregometry (Chrono-log). b Bar graph comparing the effect of Reopro $(25 \mu \mathrm{g} / \mathrm{mL})$ and RGDS $(100 \mu \mathrm{M})$ on NET-induced platelet aggregation. Platelet aggregation percentage was calculated after $20 \mathrm{~min}$ on a light transmission aggregometer. Results were normalised for each donor relative to NET-induced platelet aggregation. Data are expressed as mean $\pm \mathrm{SEM}_{1}^{* * *} P<.001$. c-f Bar graphs comparing the effect of Reopro $(25 \mu \mathrm{g} / \mathrm{mL}) \mathrm{and}$ RGDS (100 $\mu \mathrm{M})$ on platelet activation (measured by P-selectin and active allbß3 expression, $n=3)$ and ATP/ADP secretion $(n=5)$ elicited by NETs. In all assays, NETs constituted 10\% of final reaction volume and contains $292 \pm 172 \mathrm{pg} / \mathrm{mL}$ of NET-elastase. Results were normalised for each donor relative to NET-induced platelet response. Data are expressed as mean $\pm \mathrm{SEM},{ }^{*} P<0.05$; ${ }^{* *} P<0.01$, ns: non-significant

NET-induced thrombosis [59], inhibition of platelet activity may not only reduce thrombosis but also platelet-mediated inflammation. Indeed, Jansen et al., have recently shown that platelet inhibition with clopidogrel was superior to DNase in reducing granulocyte activation, NET formation and acute kidney injury in a renal reperfusion injury mice model [31]. Apart from NETs inducing thrombosis, Cedervall et al. also showed that the use of DNase to disrupt tumour-induced NETs resulted in decreased neutrophil-platelet complexes in the kidney vasculature, along with improved vascular function in tumour-bearing mice [60]. Thus in these contexts NETs can also be considered as scaffold for platelets that drives inflammatory reactions.

\section{Conclusion}

This study showed for the first time that in vitro generated NETs can directly induce marked platelet 
aggregation. We further identified the molecular pathways activated in platelet responses to NETs. It is important to note that aspirin, a widely used antiplatelet, was not as effective at reducing NET-induced platelet aggregation as ticagrelor or Reopro. Finally, pretreatment of NETs with DNase or heparin did not reduce NET-induced activation or aggregation of human washed platelets. Taken together, we conclude that targeting certain platelet activation pathways rather than NET scaffold has a more profound reduction on NET-induced platelet aggregation. Further in vitro studies are needed to compare the effect of different inhibitors on NET-induced platelet responses in a more complex system such as under flow conditions.

\section{Additional file}

Additional file 1: Supplementary data and figures. (PPTX $432 \mathrm{~kb}$ )

\section{Abbreviations}

ADP: Adenosine diphosphate; ATP: Adenosine triphosphate; Cat G: Cathepsin G; CTH: Calf thymus histones; Hep: Heparin; MPO: Myeloperoxidase; NETs: Neutrophil extracellular traps; TLR: Toll-like receptor; Tyr: Tyrosine

\section{Acknowledgements}

The authors acknowledge financial and infrastructure support from the Faculty of Health Sciences, Curtin Health Innovation Research Institute and School of Pharmacy and Biomedical Sciences, Curtin University. We also gratefully acknowledge the funding provided by the Curtin University Health Sciences Faculty International Research Scholarship for O.E and Australian Rotary Health/Jane Loxton PhD Scholarship for N.A. We would like to acknowledge the contribution of an Australian Government Research Training Program Scholarship in supporting this research.

\section{Funding}

The project was kindly funded by the Faculty of Health Sciences, Curtin University.

\section{Availability of data and materials}

All data generated in this study are included in the manuscript.

\section{Authors' contributions}

$\mathrm{OE}$ and PM contributed to the conception and the design of the study; OE and NA performed the experiments; PM, OE and NA analysed and interpreted the data; OE drafted the article; NA and PM revised the article. All authors read and approved the final manuscript.

\section{Ethics approval and consent to participate}

Venous blood was drawn from healthy volunteers with informed consent in concordance with the Curtin University Human Research Ethics Committee (approval number HR54/2014).

\section{Competing interests}

The authors declare that they have no competing interests.

\section{Publisher's Note}

Springer Nature remains neutral with regard to jurisdictional claims in published maps and institutional affiliations.
Received: 1 March 2018 Accepted: 15 May 2018

Published online: 29 May 2018

\section{References}

1. Kolaczkowska E, Kubes P. Neutrophil recruitment and function in health and inflammation. Nat Rev Immunol. 2013;13:159-75.

2. Brinkmann V, Reichard U, Goosmann C, Fauler B, Uhlemann Y, Weiss DS, Weinrauch Y, Zychlinsky A. Neutrophil extracellular traps kill Bacteria. Science. 2004;303:1532-5.

3. McDonald B, Urrutia R, Yipp Bryan G, Jenne Craig N, Kubes P. Intravascular neutrophil extracellular traps capture Bacteria from the bloodstream during Sepsis. Cell Host Microbe. 2012;12:324-33.

4. Jorch SK, Kubes P. An emerging role for neutrophil extracellular traps in noninfectious disease. Nat Med. 2017;23:279-87.

5. Wong SL, Demers M, Martinod K, Gallant M, Wang YM, Goldfine AB, Kahn CR, Wagner DD. Diabetes primes neutrophils to undergo NETosis, which impairs wound healing. Nat Med. 2015;21:815.

6. Hakkim A, Furnrohr BG, Amann K, Laube B, Abu Abed U, Brinkmann V, Herrmann M, Voll RE, Zychlinsky A. Impairment of neutrophil extracellular trap degradation is associated with lupus nephritis. Proc Natl Acad Sci U S A. 2010;107:9813-8

7. Gupta A, Hasler P, Gebhardt S, Holzgreve W, Hahn S. Occurrence of neutrophil extracellular DNA traps (NETs) in pre-eclampsia: a link with elevated levels of cell-free DNA? Ann N Y Acad Sci. 2006:1075:118-22.

8. Demers M, Krause DS, Schatzberg D, Martinod K, Voorhees JR, Fuchs TA, scadden DT, Wagner DD. Cancers predispose neutrophils to release extracellular DNA traps that contribute to cancer-associated thrombosis. Proc Natl Acad Sci U S A. 2012;109:13076-81.

9. Fuchs TA, Brill A, Duerschmied D, Schatzberg D, Monestier M, Myers DD, Wrobleski SK, Wakefield TW, Hartwig JH, Wagner DD. Extracellular DNA traps promote thrombosis. Proc Natl Acad Sci U S A. 2010;107:15880-5.

10. Martinod K, Demers M, Fuchs TA, Wong SL, Brill A, Gallant M, Hu J, Wang $Y$, Wagner DD. Neutrophil histone modification by peptidylarginine deiminase 4 is critical for deep vein thrombosis in mice. Proc Natl Acad Sci. 2013:110:8674-9.

11. von Brühl M-L, Stark K, Steinhart A, Chandraratne S, Konrad I, Lorenz M, Khandoga A, Tirniceriu A, Coletti R, Köllnberger M, et al. Monocytes, neutrophils, and platelets cooperate to initiate and propagate venous thrombosis in mice in vivo. J Exp Med. 2012;209:819-35.

12. Abdol Razak N, Elaskalani O, Metharom P. Pancreatic Cancer-induced neutrophil extracellular traps: a potential contributor to Cancer-associated thrombosis. Int J Mol Sci. 2017;18:1-18.

13. Leal AC, Mizurini DM, Gomes T, Rochael NC, Saraiva EM, Dias MS, Werneck CC, Sielski MS, Vicente CP, Monteiro RQ. Tumor-derived Exosomes induce the formation of neutrophil extracellular traps: implications for the establishment of Cancer-associated thrombosis. Sci Rep. 2017;7:6438.

14. McDonald B, Davis RP, Kim S-J, Tse M, Esmon CT, Kolaczkowska E, Jenne CN Platelets and neutrophil extracellular traps collaborate to promote intravascular coagulation during sepsis in mice. Blood. 2017;129:1357-67.

15. Gould TJ, Vu TT, Swystun LL, Dwivedi DJ, Mai SHC, Weitz JI, Liaw PC. Neutrophil extracellular traps promote thrombin generation through platelet-dependent and platelet-independent mechanisms. Arterioscler Thromb Vasc Biol. 2014;34:1977-84.

16. Swystun LL, Mukherjee S, Liaw PC. Breast cancer chemotherapy induces the release of cell-free DNA, a novel procoagulant stimulus. J Thromb Haemost. 2011:9:2313-21.

17. Ammollo CT, Semeraro F, Xu J, Esmon NL, Esmon CT. Extracellular histones increase plasma thrombin generation by impairing thrombomodulindependent protein C activation. J Thromb Haemost. 2011;9:1795-803.

18. Semeraro F, Ammollo CT, Morrissey JH, Dale GL, Friese P, Esmon NL, Esmon CT. Extracellular histones promote thrombin generation through platelet-dependent mechanisms: involvement of platelet TLR2 and TLR4. Blood. 2011:118:1952-61.

19. Fuchs TA, Bhandari AA, Wagner DD. Histones induce rapid and profound thrombocytopenia in mice. Blood. 2011;118:3708-14.

20. Clark SR, Ma AC, Tavener SA, McDonald B, Goodarzi Z, Kelly MM, Patel KD, Chakrabarti S, McAvoy E, Sinclair GD, et al. Platelet TLR4 activates neutrophil extracellular traps to ensnare bacteria in septic blood. Nat Med. 2007;13:463.

21. Massberg S, Grahl L, von Bruehl M-L, Manukyan D, Pfeiler S, Goosmann C, Brinkmann V, Lorenz M, Bidzhekov K, Khandagale AB, et al. Reciprocal 
coupling of coagulation and innate immunity via neutrophil serine proteases. Nat Med. 2010;16:887-96.

22. Gorudko IV, Sokolov AV, Shamova EV, Grudinina NA, Drozd ES, Shishlo LM, Grigorieva DV, Bushuk SB, Bushuk BA, Chizhik SA, et al. Myeloperoxidase modulates human platelet aggregation via actin cytoskeleton reorganization and store-operated calcium entry. Biology Open. 2013;2:916-23.

23. Carrim N, Arthur JF, Hamilton JR, Gardiner EE, Andrews RK, Moran N, Berndt MC, Metharom P. Thrombin-induced reactive oxygen species generation in platelets: a novel role for protease-activated receptor 4 and GPIbalpha. Redox Biol. 2015:6:640-7.

24. Radomski M, Moncada S. An improved method for washing of human platelets with prostacyclin. Thromb Res. 1983;30:383-9.

25. Najmeh S, Cools-Lartigue J, Giannias B, Spicer J, Ferri LE. Simplified human neutrophil extracellular traps (NETs) isolation and handling. J Vis Exp. 2015:1-6.

26. Urban CF, Ermert D, Schmid M, Abu-Abed U, Goosmann C, Nacken W, Brinkmann V, Jungblut PR, Zychlinsky A. Neutrophil extracellular traps contain Calprotectin, a cytosolic protein complex involved in host defense against Candida albicans. PLoS Pathog. 2009;5:1-18.

27. Bennett JS. Structure and function of the platelet integrin alphallbbeta3. J Clin Invest. 2005;115:3363-9.

28. Zwaal RF, Schroit AJ. Pathophysiologic implications of membrane phospholipid asymmetry in blood cells. Blood. 1997;89:1121-32.

29. Alshehri OM, Montague S, Watson S, Carter P, Sarker N, Manne BK, Miller JL, Herr AB, Pollitt AY, O'Callaghan CA, et al. Activation of glycoprotein VI (GPVI) and C-type lectin-like receptor-2 (CLEC-2) underlies platelet activation by diesel exhaust particles and other charged/hydrophobic ligands. Biochem J. 2015:468:459-73.

30. Fuchs TA, Brill A, Duerschmied D, Schatzberg D, Monestier M, Myers DD Jr, Wrobleski SK, Wakefield TW, Hartwig JH, Wagner DD. Extracellular DNA traps promote thrombosis. Proc Natl Acad Sci U S A. 2010;107:15880-5.

31. Jansen MP, Emal D, Teske GJ, Dessing MC, Florquin S, Roelofs JJ. Release of extracellular DNA influences renal ischemia reperfusion injury by platelet activation and formation of neutrophil extracellular traps. Kidney Int. 2017;91:352-64.

32. Pal PK, Starr T, Gertler MM. Neutralization of heparin by histone and its subfractions. Thromb Res. 1983;31:69-79.

33. Taylor L, Vasudevan SR, Jones Cl, Gibbins JM, Churchill GC, Campbell RD, Coxon CH. Discovery of novel GPVI receptor antagonists by structure-based repurposing. PLoS One. 2014;9:e101209.

34. Jiang P, Loyau S, Tchitchinadze M, Ropers J, Jondeau G, Jandrot-Perrus M. Inhibition of glycoprotein VI clustering by collagen as a mechanism of inhibiting collagen-induced platelet responses: the example of losartan. PLoS One. 2015;10:1-20.

35. Elaskalani O, Khan I, Morici M, Matthysen C, Sabale M, Martins RN, Verdile G, Metharom P. Oligomeric and fibrillar amyloid beta 42 induce platelet aggregation partially through GPVI. Platelets. 2017;29:415-20.

36. Faraday N, Schunke K, Saleem S, Fu J, Wang B, Zhang J, Morrell C, Dore S. Cathepsin G-dependent modulation of platelet thrombus formation in vivo by blood neutrophils. PLoS One. 2013;8:e71447.

37. Kolarova H, Klinke A, Kremserova S, Adam M, Pekarova M, Baldus S, Eiserich JP, Kubala L. Myeloperoxidase induces the priming of platelets. Free Radic Biol Med. 2013:61:357-69.

38. Walsh TG, Berndt MC, Carrim N, Cowman J, Kenny D, Metharom P. The role of Nox1 and Nox2 in GPVI-dependent platelet activation and thrombus formation. Redox Biol. 2014;2:178-86.

39. Metharom P, Berndt MC, Baker RI, Andrews RK. Current state and novel approaches of antiplatelet therapy. Arterioscler Thromb Vasc Biol. 2015; 35:1327-38.

40. Estensen RD, White JG. Ultrastructural features on the platelet response to phorbol myristate acetate. Am J Pathol. 1974;74:441-52.

41. Lu Q, Clemetson JM, Clemetson KJ. Translocation of GP1b and fc receptor gamma-chain to cytoskeleton in mucetin-activated platelets. J Thromb Haemost. 2005:3:2065-76.

42. Bevers EM, Comfurius P, Zwaal RF. Changes in membrane phospholipid distribution during platelet activation. Biochim Biophys Acta. 1983;736:57-66

43. Rosing J, van Rijn JL, Bevers EM, van Dieijen G, Comfurius P, Zwaal RF. The role of activated human platelets in prothrombin and factor $X$ activation. Blood. 1985;65:319-32.

44. Tonon G, Luo X, Greco NJ, Chen W, Shi Y, Jamieson GA. Weak platelet agonists and U46619 induce apoptosis-like events in platelets, in the absence of phosphatidylserine exposure. Thromb Res. 2002;107:345-50.
45. Carestia A, Rivadeneyra L, Romaniuk MA, Fondevila C, Negrotto S, Schattner M. Functional responses and molecular mechanisms involved in histonemediated platelet activation. Thromb Haemost. 2013;110:1035-45.

46. Dorsch CA. Binding of single-strand DNA to human platelets. Thromb Res. 1981:24:119-29.

47. Fiedel BA, Schoenberger JS, Gewurz H. Modulation of platelet activation by native DNA. J Immunol. 1979:123:2479-83.

48. Fiedel BA, Frenzke ME. Modulation of platelet aggregation by native DNA initial description of platelet receptor type, number and discrimination for native DNA. Thromb Haemost. 1981;45:263-6.

49. Noubouossie DF, Whelihan MF, Yu Y-B, Sparkenbaugh E, Pawlinski R, Monroe DM, Key NS. In vitro activation of coagulation by human neutrophil DNA and histone proteins but not neutrophil extracellular traps. Blood. 2017;129:1021-9.

50. Sambrano GR, Huang W, Faruqi T, Mahrus S, Craik C, Coughlin SR. Cathepsin $\mathrm{G}$ activates protease-activated receptor-4 in human platelets. J Biol Chem. 2000;275:6819-23.

51. Korkmaz B, Horwitz MS, Jenne DE, Gauthier F. Neutrophil Elastase, proteinase 3, and Cathepsin $\mathrm{G}$ as therapeutic targets in human diseases. Pharmacol Rev. 2010;62:726-59.

52. Si-Tahar M, Pidard D, Balloy V, Moniatte M, Kieffer N, VanDorsselaer A, Chignard M. Human neutrophil elastase proteolytically activates the platelet integrin alpha(llb)beta(3) through cleavage of the carboxyl terminus of the alpha(IIB) subunit heavy chain - involvement in the potentiation of platelet aggregation. J Biol Chem. 1997;272:11636-47.

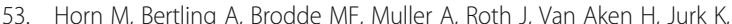
Heilmann C, Peters G, Kehrel BE. Human neutrophil alpha-defensins induce formation of fibrinogen and thrombospondin-1 amyloid-like structures and activate platelets via glycoprotein IIb/llla. J Thromb Haemost. 2012;10:647-61.

54. Fuentes E, Rojas A, Palomo I. Role of multiligand/RAGE axis in platelet activation. Throm Res. 2014;133:308-14.

55. Papayannopoulos V. Neutrophil extracellular traps in immunity and disease. Nat Rev Immunol. 2018:18:134-47.

56. Carmona-Rivera C, Zhao WP, Yalavarthi S, Kaplan MJ. Neutrophil extracellular traps induce endothelial dysfunction in systemic lupus erythematosus through the activation of matrix metalloproteinase-2. Ann Rheum Dis. 2015; 74:1417-24.

57. Rajagopalan S, Somers EC, Brook RD, Kehrer C, Pfenninger D, Lewis E, Chakrabarti A, Richardson BC, Shelden E, McCune WJ, Kaplan MJ. Endothelial cell apoptosis in systemic lupus erythematosus: a common pathway for abnormal vascular function and thrombosis propensity. Blood. 2004:103:3677-83

58. Dovizio M, Alberti S, Guillem-Llobat P, Patrignani P. Role of platelets in inflammation and Cancer: novel therapeutic strategies. Basic Clin Pharmacol Toxicol. 2014;114:118-27.

59. Brill A, Fuchs TA, Savchenko AS, Thomas GM, Martinod K, De Meyer SF, Bhandari AA, Wagner DD. Neutrophil extracellular traps promote deep vein thrombosis in mice. J Thromb Haemost. 2012:10:136-44.

60. Cedervall J, Zhang Y, Huang H, Zhang L, Femel J, Dimberg A, Olsson A-K. Neutrophil extracellular traps accumulate in peripheral blood vessels and compromise organ function in tumor-bearing animals. Cancer Res. 2015;75:2653-62.

\section{Ready to submit your research? Choose BMC and benefit from:}

- fast, convenient online submission

- thorough peer review by experienced researchers in your field

- rapid publication on acceptance

- support for research data, including large and complex data types

- gold Open Access which fosters wider collaboration and increased citations

- maximum visibility for your research: over $100 \mathrm{M}$ website views per year

At BMC, research is always in progress.

Learn more biomedcentral.com/submissions 